\title{
A co-experience toolkit: investigating the issues of the pavement environment and the relationship with elderly pedestrians
}

\author{
YIN Lulu ${ }^{a} ;$ PEI Eujin ${ }^{b}$ and YIN Lulu ${ }^{a^{*}}$ \\ ${ }^{a}$ Department of Design, College of Engineering, Design and Physical Science, Brunel University London \\ ${ }^{b}$ Department of Design, College of Engineering, Design and Physical Science, Brunel University London \\ * Corresponding author e-mail: lulu.yin@brunel.ac.uk \\ doi: $10.21606 /$ dma.2017.328
}

\begin{abstract}
Pedestrian pavements play an important role in assisting or restricting the quality of walking. Poorly designed and maintained pavements may pose a challenge to the walking experience of older adults. This research aims to investigate pavement problems and their effects on elderly pedestrians. An empirical study was conducted in London with 41 older people aged over 60 who were fit to walk. In this study, we classified 16 influencing factors of the pavements and four adverse effects of them and identified 13 behaviours that elderly pedestrians displayed when they encountered the pavement factors. In addition, 17 recommendations were proposed in order to improve the pavement environment based on the requirement of the elderly pedestrians. Taking a step further, we developed a co-experience toolkit that could be used by researchers and professionals involved in the study of pavement design and urban planning to assess and improve the pavement environment with older adults. This toolkit is designed to encourage the users to understand the relationship between pavements and elderly pedestrians better.
\end{abstract}

pedestrian pavement, older people, behaviour change, built environment, design tool

\section{Introduction}

According to Shrestha (2016), older adults have a higher frequency of walking compared to driving or taking public transport. This form of transport has drawn the attention of many researchers examining how the built environment can influence the walking experience of elderly people (Frank et al., 2010; Ewing \& Cervero, 2010). For instance, pavements have been recognised as an important factor to encourage walking and to increase the amount of walking activity (Choi, 2012; Lo, 2009). Publications, such as the 'Manual for Streets' by Department for Transport (2007) and 'Pedestrian Comfort Guidance for London' by Transport for London (2010), have highlighted key issues of the 
pavement and created design guidelines for the pavements. For example, pavement conditions and barriers of both static and moving obstructions can influence the level of access, which in turn have implications for pedestrians' safety and their quality of walking (Rackliff, 2013).

Some research approaches and tools have been designed to evaluate and monitor the quality of the pavement and to collect the feedback of pavement users. For example, local authorities in London have set up a web page for residents to report the problems of roads and pavements ("London Borough of Hillingdon - Report potholes or damage", n.d.). Volunteers have been recruited as "Street Champions" to record and detect the conditions of pavements ("London Borough of Hillingdon- Street Champions", n.d.). Tools, such as an 'Audit checklist' (Curl, 2016), help to evaluate the risks of older adults when walking along pavements, such as falls.

Although the existing studies and approaches cover general information about outdoor walking, they do not investigate how the pavement conditions influence the walking behaviour of elderly pedestrians. In summary, the relationship between pavements and older adults' walking experience is decidedly less discussed regarding the impacts of pavements on elderly pedestrians especially their physically behavioural aspects. The perspective of older people to the pavement is also less understood. To investigate this further, we set out three main research questions: (1) what are the factors of the pavement environment influencing the elderly pedestrians; (2) what are the behavioural changes of the elderly pedestrian walking on the pavement; and (3) what is the relationship between the pavement environment and elderly pedestrians.

\section{The empirical study}

An empirical study was organised to investigate the factors of the pavement that could influence the walking behaviour of elderly pedestrians and collected the requirements for improving the pavement. 41 older people ( 9 for stage-one and 32 for stage-two) from London were recruited to participate in the study. There were similar ratios of male and female participants ( 22 females and 19 males) who were either retired or semi-retired. The participants were needed to be above 60 years old and fit to walk. The pavement environment in Hillingdon, Ealing and Camden of London were chosen for the research because a large number of senior residents whose walking significantly engaged in the pavement lived in the vicinity.

Table 1 Methods of the study.

\begin{tabular}{|c|c|c|c|}
\hline \multicolumn{3}{|l|}{ Stage-one $(n=9)$} & \multirow[b]{2}{*}{ Collected data } \\
\hline Aim & Research techniques & Duration & \\
\hline $\begin{array}{l}\text { Investigating the } \\
\text { influencing factors of the } \\
\text { pavement }\end{array}$ & Interviews & 45 minutes & $\begin{array}{l}\text { Personal opinions of } \\
\text { the participants }\end{array}$ \\
\hline $\begin{array}{l}\text { Exploring the behavioural } \\
\text { changes of the elderly } \\
\text { pedestrians }\end{array}$ & Observations & $\begin{array}{l}\text { Two rounds: } 30 \text { to } 60 \\
\text { minutes per round }\end{array}$ & $\begin{array}{l}\text { Findings beyond the } \\
\text { perspectives of the } \\
\text { participants }\end{array}$ \\
\hline $\begin{array}{l}\text { Collecting the } \\
\text { recommendations for } \\
\text { improving the pavement }\end{array}$ & Cultural probes & 3 to 7 days & $\begin{array}{l}\text { Covered information } \\
\text { reported by the } \\
\text { participants }\end{array}$ \\
\hline \multicolumn{4}{|l|}{ Stage-two $(n=32)$} \\
\hline Aim & Research techniques & Duration & Collected data \\
\hline $\begin{array}{l}\text { Quantifying the collected } \\
\text { data }\end{array}$ & $\begin{array}{l}\text { A mix of interview and } \\
\text { questionnaire }\end{array}$ & 60 minutes & $\begin{array}{l}\text { The priority of the } \\
\text { collected data }\end{array}$ \\
\hline
\end{tabular}

In stage-one, the data collection was carried out with 9 participants using a set of interviews, observations and cultural probes to gain insights into their walking experience and their perspectives about the quality of the pavement. Additionally, the participants' behavioural changes and the pavement problems in the surroundings of their residence are observed and recorded using 
photographs. The interview was used to fully understand and record the in-depth views of the participants (Silverman, 2010). A question book was offered to the participants investigating the pavement issues and their particular experience on the pavement. In the observation, the hazards to the participants on the pavement were identified, and their actions beyond their perspectives were captured (Gray, 2014). The cultural probe known as a self-reporting tool was used by the participants to record the phenomenon that was exposed when they were walking alone (Arthur, 2012). It consisted of a diary booklet, a disposable camera, a local map and two pens which enabled the participants to photograph, mark and report the information. At the end of stage-one, plenty of data was received, while the significant findings needed to be further verified with a more substantial number of samples. Therefore in stage-two, a mixed method of interview and questionnaire was employed to specify the priority of the findings by quantifying the data efficiently (Ravitch \& Carl, 2016). This combination assisted the participants to understand the study enquires better, therefore, generating valid data (Hussein, 2009). Finally, 32 participants filled out the questionnaires, and all the questions were completed with valid responses.

To analyse the substantial data, descriptive coding was used to categorise and generalise the scripts into words and short phrases (Miles, Huberman \& Saldana, 2014). The collected results were then grouped into 16 influencing factors of pavements, 13 associated behavioural changes, 4 categories of adverse effects and 17 recommendations to improve the quality of the for pavement environments. 


\subsection{Findings and discussion}

Table 2 Influencing factors of the pavement and their adverse impacts.

\begin{tabular}{|c|c|c|}
\hline \multicolumn{2}{|r|}{$\begin{array}{l}\text { Factors of the pavement environment that influence the walking of } \\
\text { elderly pedestrians }\end{array}$} & $\begin{array}{l}\text { Adverse effects of the pavement } \\
\text { factors }\end{array}$ \\
\hline 1 & Uneven pavements & \multirow{16}{*}{$\begin{array}{l}\text { - Increasing the risk of falling } \\
\text { and being tripping } \\
\text { - Increasing negative physical } \\
\text { impacts } \\
\text { (tiredness and pains) } \\
\text { - Limiting one's walking } \\
\text { (limiting one's walking activity } \\
\text { or behaviours) }\end{array}$} \\
\hline 2 & $\begin{array}{l}\text { Overgrown plants } \\
\text { (overgrown bushes and trunks, overhanging branches and } \\
\text { ruderal) }\end{array}$ & \\
\hline 3 & $\begin{array}{l}\text { Slippery obstacles } \\
\text { (slippery paving surfaces, liquid, ice, snow, fallen leaves, and } \\
\text { moss) }\end{array}$ & \\
\hline 4 & Broken pavements & \\
\hline 5 & $\begin{array}{l}\text { Moving objects } \\
\text { (bicycles, mobile scooters and skateboarders) }\end{array}$ & \\
\hline 6 & $\begin{array}{l}\text { Temporary obstacles } \\
\text { (rubbish and temporarily placed objects on pavements) }\end{array}$ & \\
\hline 7 & $\begin{array}{l}\text { Street infrastructure and furniture } \\
\text { (poorly planned or maintained street lights, cable boxes, street } \\
\text { signs, bins, benches and bus stops) }\end{array}$ & \\
\hline 8 & $\begin{array}{l}\text { Manhole and drain covers } \\
\text { (contributing to uneven and slippery surfaces) }\end{array}$ & \\
\hline 9 & Parked vehicles & \\
\hline 10 & $\begin{array}{l}\text { Constructions } \\
\text { (safety barriers; build and repair works of road, pavements and } \\
\text { street buildings) }\end{array}$ & \\
\hline 11 & $\begin{array}{l}\text { Narrow pavements } \\
\text { (the paving width of pavement is narrow, or pavements are } \\
\text { occupied by obstacles) }\end{array}$ & \\
\hline 12 & $\begin{array}{l}\text { Absence of pavement } \\
\text { (no paved path for pedestrians) }\end{array}$ & \\
\hline 13 & $\begin{array}{l}\text { Street stores } \\
\text { (commercial objects; tables and chair; and booths) }\end{array}$ & \\
\hline 14 & $\begin{array}{l}\text { Confusing paving patterns } \\
\text { (messy paving slabs) }\end{array}$ & \\
\hline 15 & Tactile paving areas & \\
\hline 16 & Stepped and sloping ground & \\
\hline
\end{tabular}

Table 2 shows 16 key factors that influence the participants' walking and records the negative impact such as the risk of falling. In consonance with Oxley and Hern (2016) and Wang et al. (2016), this study also found that slippery, uneven and poorly maintained pavements, and pavements with missing slabs, and kerbs, and inadequate street lighting were common hazards which would increase the fall risk. Our participants additionally reported that protruding tree roots, street infrastructure and drain covers would contribute to the risk of slips and falls. Besides, they indicated that narrow pavements made them have difficulty in navigating along the path. Furthermore, the pavements would be narrowed by permanent obstacles and further affected older people walking on the road (I'DGO, n.d.). Contrasting colours of ground patterns were sometimes mistaken for changes in the ground level (Pollock, 2012). Some participants also claimed that they experience physical discomfort when walking on poor ground surfaces. For example, the unevenness of pavements resulted in pain in their ankles and the overgrown tree branches compelled them to bend down and led to neck pain. Moreover, they experienced tiredness when they had to spend extra energy to walk up and down on the slopes. Although tactile paving is designed to support the walking of 
people with visual impairments, it can be a hazard as it can create slippery and uneven surfaces (I'DGO, 2010); therefore, it made older adults fall and unstable and further initiated pain in their hip and ankles.

Table 3 Behavioural changes of the elderly pedestrians.

\begin{tabular}{|l|l|}
\hline \multicolumn{2}{|l|}{ Behavioural changes of the elderly pedestrian } \\
\hline 1 & Adopting cautious steps \\
\hline 2 & Walking around \\
\hline 3 & Adjusting paces \\
\hline 4 & Walking slowly \\
\hline 5 & Giving way to other pedestrians \\
\hline 6 & Stopping walking \\
\hline 7 & Walking on the outside of pavement \\
\hline 8 & Walking on the road \\
\hline 9 & Crossing to the opposite side \\
\hline 10 & Lowering one's head \\
\hline 11 & Raising steps \\
\hline 12 & Facing oncoming traffic \\
\hline 13 & Swerving one's body \\
\hline
\end{tabular}

Table 3 presents 13 main behavioural changes that the elderly pedestrians adopted when encountering the influencing factors of the pavement. For example, they usually walked with careful steps to cope with the pavement issues. Sometimes they intentionally walked away from the obstacles; adjusted their pacing more often; walked slowly; raised their steps higher; and gave way for other pedestrians to mitigate the risk. This is in line with previous studies that show that they slowed down the pace of their steps when facing potential hazards (Spirduso, Francis \& MacRae, 2005); and those who encountered irregular surfaces often adopted a more conservative gait pattern to negotiate the uneven ground (Mitra, Siva, \& Kehler, 2015). Walking on the outside of the pavement was also a main tactic of the participants when the width of pavements was comprised of environmental obstacles, such as overgrown plants and inappropriate street furniture. Furthermore, the participants were compelled to walk on the road or to cross to the other side when the pavement was in severely slippery and broken condition; when a pavement was not available and when there was no designated footpath. At the same time of walking on the road, they usually faced oncoming vehicles so that they could observe the traffic flow. In fact, facing oncoming vehicles could reduce the number of injuries caused by traffic (Luoma \& Peltola, 2013). At times, the participants would stop to observe before deciding how to deal with a situation to avoid the risk involved. For example, they stopped walking before stepping onto a slippery surface or when a cyclist was approaching. Besides, it was observed that the participants had to lower their head while avoiding the overhanging branches; or to look down on the pavement and observe the ground condition.

In this study, recommendations were also collected to improve the quality of the pavements. We also took on board the resources from the government publications and standards to pavement design, such as HD 39/16 (DMRB, 2016), Manual for Street (DfT, 2007) and Pedestrian Comfort Guidance for London (TFL, 2010), and references from other notable studies, such as Bayliss (2015) and Rackliff (2013). In summary, the recommendations include having:

- even and smooth paving surfaces

- wide pavements

- non-slippery paving materials

- well-maintained pavements

- clear pavements free from obstacles, such as temporary obstacles and parked cars 
- well-constructed and organised street infrastructure and furniture

- a well-defined pedestrian route separated from constructions or vehicle roads

- fewer step and slope ground or they are built on a small gradient

- well-cared plants and right kinds of plants

- low kerbs

- pedestrianized pavements and plan the pavement for different users, such as scooters and cyclists

- taking away the temporary obstacles immediately or managing them well

- functional markings indicate the problems of pavements

- clear paving patterns in a uniform design

- well-maintained manhole and drain covers

- street stores make more space for pedestrians

- tactile paving planned for appropriate size and in appropriate locations

\section{Concept development}

The result of the data collection was concluded and embodied into a database with infographic displays. In addition to the database, a decision was made to develop a tool that could be utilised to assess and improve the pavement environment. This toolkit is designed to encourage users to gain a better understanding of the relationship between pavements and elderly pedestrians. For the first phase, we analysed existing approaches and tools which were designed to do reports and monitor the issues of the pavement. For example, FixMyStreet application ("FixMyStreet", n.d.) allows users to report the local problems like graffiti, fly tipping, broken paving slabs, or street lighting with photographs and descriptions. It then sends the organised reports to the local council and presents the problems on a digital map. Based on the ideas, we developed the concept including an analysis map and a demonstration card-pack which were used to probe the pavement environment. The analysis map was in a neutral design layout, and it was simulated as a pavement environment in which problems could be identified with the 'locating icons' reprinting different pavement issues. Users could assume the map as a local pavement environment and marked significant building and street names on the map. Then they could use the locating icons to demonstrate pavement hazards like the uneven pavements, narrow pavement and plants. Further discussions would be generated based on the map and elicit more relevant findings. In addition to the map, the card-pack includes 16 foldable cards which reported the significant findings of the empirical study: (1) the description and photos of different pavement factors, (2) the impact of poor pavements on elderly pedestrians, (3) changes to their walking behaviour; and (4) recommendations for built pavements. Users could use the analysis map to investigate issues of the pavement, and then turn to the card-pack learning the relationship between the pavement and elderly pedestrians. 


\section{Analysis map with locating icons}

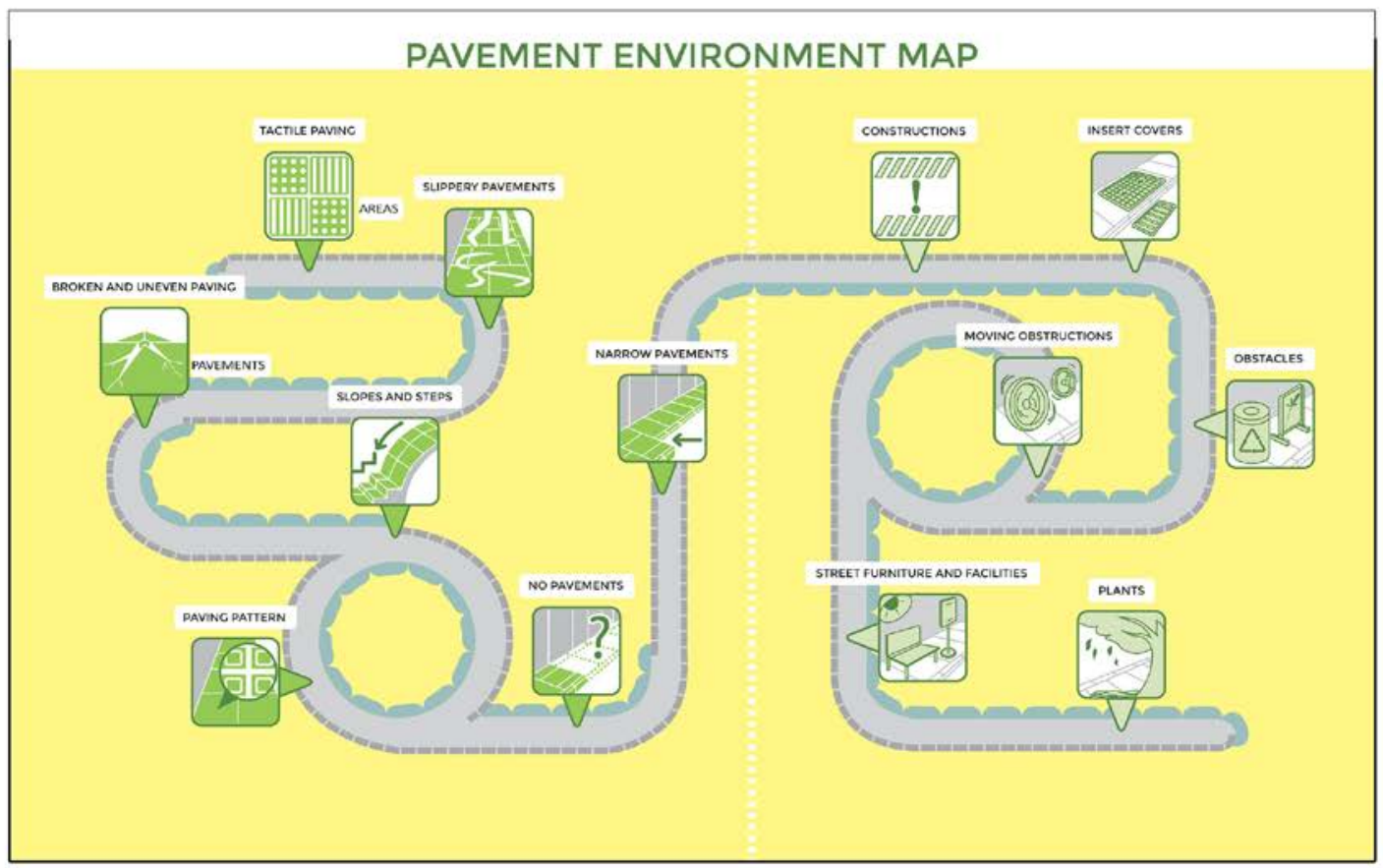

\section{Card-pack}

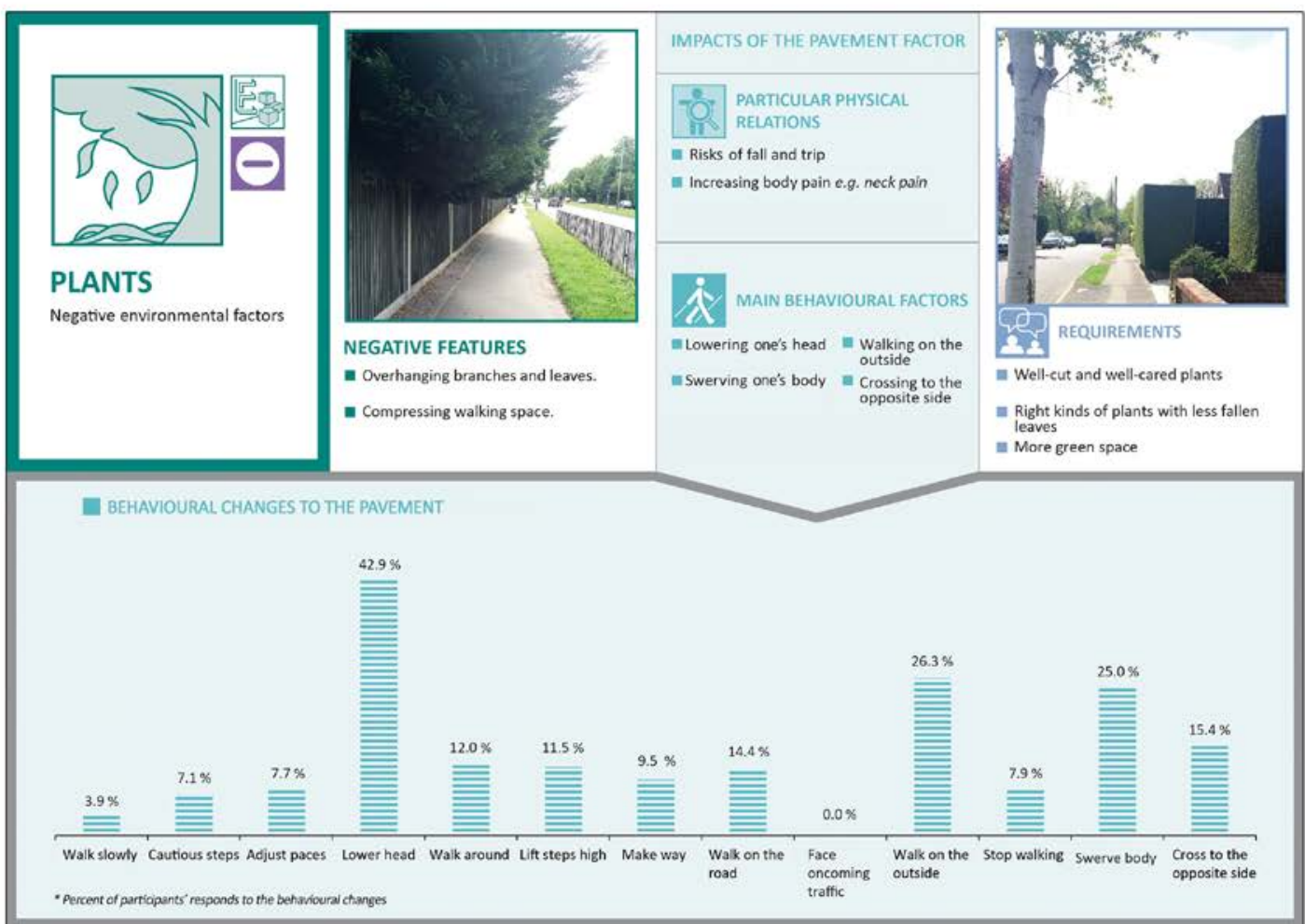

Figure 1 Design concept of the tool

\subsection{Expert interview}


In the concept stage, we invited seven academics to an interview to seek their feedback based on their different expertise such as accessibility, design methodology, inclusive design, behavioural science and civil engineering. During the interview, we discuss the information and design of the concept; application of the design concept and potential users; and recommendations for the tool.

\subsection{Comments on the design concept}

The academics declared that the tool was important and original and it provided new information in the certain research area and demonstrated a clear relationship between pavements and elderly pedestrians. It was useful in providing a better understanding of elderly people's perception of the pavement. Specifically, the analysis map highlighted the issues in a specific location. It was useful to do the investigation, and the sign planning contributed to decision making. Moreover, the card-pack was useful to provide a lot of specific content and universal solutions, and it was easy to use. The information shown on the cards urged people to look into details and to make them think about more. For example, they would consider the solutions to the pavement issue concerning its impacts on elderly pedestrians. Different information on the card showed the relationships between the pavement and older pedestrians for different users. However, personal preference to use the card would induce the miss of the information. Overall the whole view was easy to follow even though the connection between the map and card-pack could be made more explicit.

The tool would contribute to the users who are interested in the identification of the pavement issues while unfamiliar with the pavement environment. They may apply the finding in their work or use it as a checklist. They would be designers, researchers, local councillors and general public groups who worked on pavement design, environment design, urban design, place making, and community development. Moreover, the result and concepts may have a potential to be applied in academic projects. School students may use the map and card-pack to explore neighbourhoods. Lecturers can use them as a teaching tool, using it to generate guideline for an observation study and co-design.

In terms of the further development of the tool, firstly, the academics indicated that it could be used as a document or investigation tool. But if it is an idea generated tool, less information and data should be given. Secondly, the interactive process of the tool should be well designed. A tool in the physical format would be good to use practically for older adults in the real world. Thirdly, colour coding was recommended in the tool design. For example, the pavement factor could be distinguished by different colours. Fourthly, the user flow should be simplified in clarifying the information of the task that users need to complete. Finally, the tool should explain what it is, why and how it is used, and display the information that users need. It needs to deliver efficient results for people to report, produce and write something.

\section{Co-experience toolkit}

Based on the previous findings and discussion, a co-experience toolkit has been developed. It provides an opportunity for older adults to indicate their perspectives of walking on local pavements. Meanwhile, it assists people who work on designing, maintaining and monitoring the urban walking environment to assess and improve the pavements. Apparently, the users are made up of two groups of people who are 'researchers' (pavement designers, city planners and road engineers) and 'participants' (older adults who are fit to walk). This toolkit allows one researcher to conduct a co-study with up to six 'participants' every time. They could identify the problems and impacts of the pavement, and explore older pedestrians' behavioural changes to the pavement issues. In addition, they could propose recommendations in order to improve the quality of the pavement environment. In the co-experience study, participants would discuss and share their ideas in an interactive way, and consequentially the researcher could collate and model the results into the desired direction (Battarbee, 2003, cited in Fan \& Lu, 2017, p. 4).

\subsection{Components and usage of the co-experience toolkit}


The toolkit is designed in a physical format in consideration of facilitating the interactive activity and efficiently seeking for the opinion of the elder users. Matrix is the main design element of the tool, and it was used to assemble the data. Because the data in matrix could be interpreted and described straightforwardly; and the relationship in the data could be uncovered by identifying and comparing the similarities and differences in the cross-sections (Corbin \& Strauss, 2015).

This physical tool consists of four components including (1) 6 groups of 16 'Pins' and 16 'Landmarks' that each of them shows the type of a negative factor in the pavement, and being coded with a particular colour and a distinct participant code (e.g. P1, P2, or P3); (2) 6 'Participant survey books' which are used by the older adults to indicate the pavement factors that affect their walking, to specify their behaviours and to also suggest recommendations to improve the pavement; (3) A 'Card-pack' that includes 16 cards that providing descriptions of different factors of pavements using photographs and description; (4) A 'Researcher recording card' that is used by researchers to compile all data from the co-experience exercise. The recording card is in the form of a booklet that offers user instruction and tables for the researchers to record information being discussed. The user instruction introduces the background, objectives, pre-requisite materials, exercises and components of the toolkit. An additional material which is a local map that would be prepared by the researchers and printed in an appropriate scale (size A2 and $A 1$ are recommended) so that it can be easily read with clearly labelled street names and landmarks. 


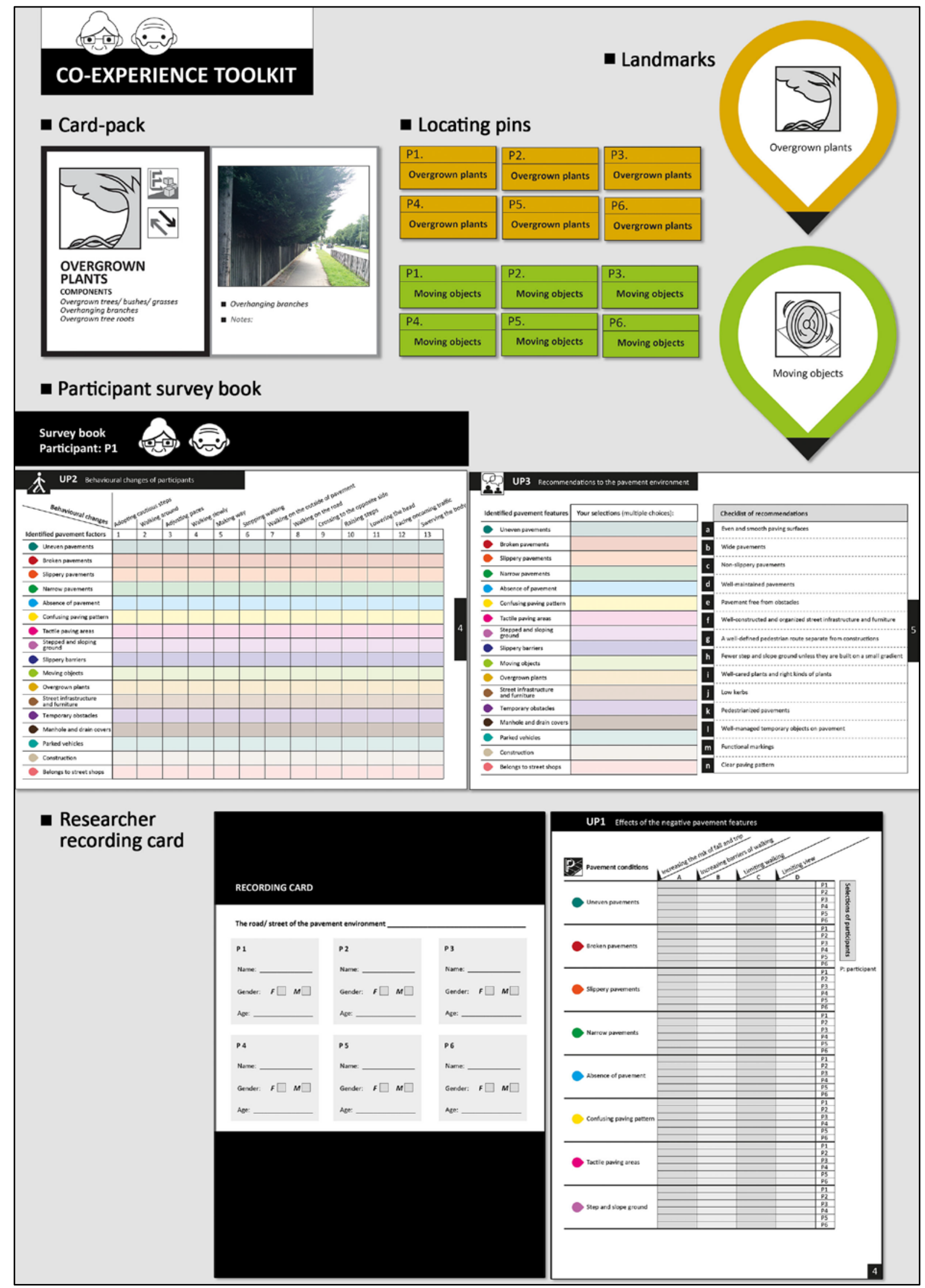

Figure 2 Components of the Co-experience toolkit

\subsection{Test of the co-experience toolkit}


To test the tool, we intended to find out if the tool shows information in a proper way; enables the users to know what they could do and how to do; provides an efficient way to collect data; ensures users do appropriate exercises; assists users to identify problems and get solutions; and enables the collected data easy to be used; or supports the researchers in their work field and expands their knowledge (Grinyer, 2016; the design guideline of "IBM Design Research | Resources | Toolkit", 2017).

\subsection{Methods}

The toolkit was evaluated by nine senior citizens aged over 60 in Hillingdon, as well as five doctoral students from civil engineering, design and ageing study to act as researchers. Each researcher was allocated to a group with two of the older adults as the participants, and overall there were five groups. The groups were asked to use the toolkit to assess and improve the pavement environment of Uxbridge town centre (London). Each group sat together with the map in the centre of the table, and the components of the toolkit were distributed among the group according to their role. Every participant got a group of 16 'Pins' and 1 'Survey book', and the researcher got the 16 'Landmarks' and a 'Recording card'. At first, the researcher collected the personal information of the participants in the 'Recording card'. Next, the researcher asked them to identify the factors of the pavement environment that would affect their walking by placing the relevant 'Pins' on the map. At the same time, the participants further discussed why they had chosen those pavement factors, and the researcher selected the significant ones based on the group discussion. Then the researcher highlighted the significant pavement factors with their corresponding 'Landmarks' on the map, and signed them in the recording card. Following that, the participants indicated the impacts of the highlighted pavement factors on them and, the behaviours that they would have shown when encountering with those pavement factors. According to the row heading of the matrix tables in the 'Survey book', the participants ticked off their responses. Finally, they made suggestions on how the pavement conditions could be improved according to a list of supplied recommendations in the 'Survey book'. At the end of the activity, the researcher compiled all of the responses from the 'Survey books' in the 'Recording card'.

After the exercise, further user comments were collected in a survey questionnaire that consisted of nine questions: (1) Is the tool easy to use?; (2) Is the toolkit efficiently designed?; (3) Does the tool include the information that you expect?; (4) Does the tool enable you to indicate your ideas?; (5) Do the objectives of the co-study were achieved using this tool?; (6) Did you obtain new knowledge from using the tool?; plus 'Does the tool enable you to collect and compile the data quickly and easily?'; 'What will you do with the results that have been collected using the tool?'; and 'How does the tool contribute to your work?' which were designed for researchers only. 


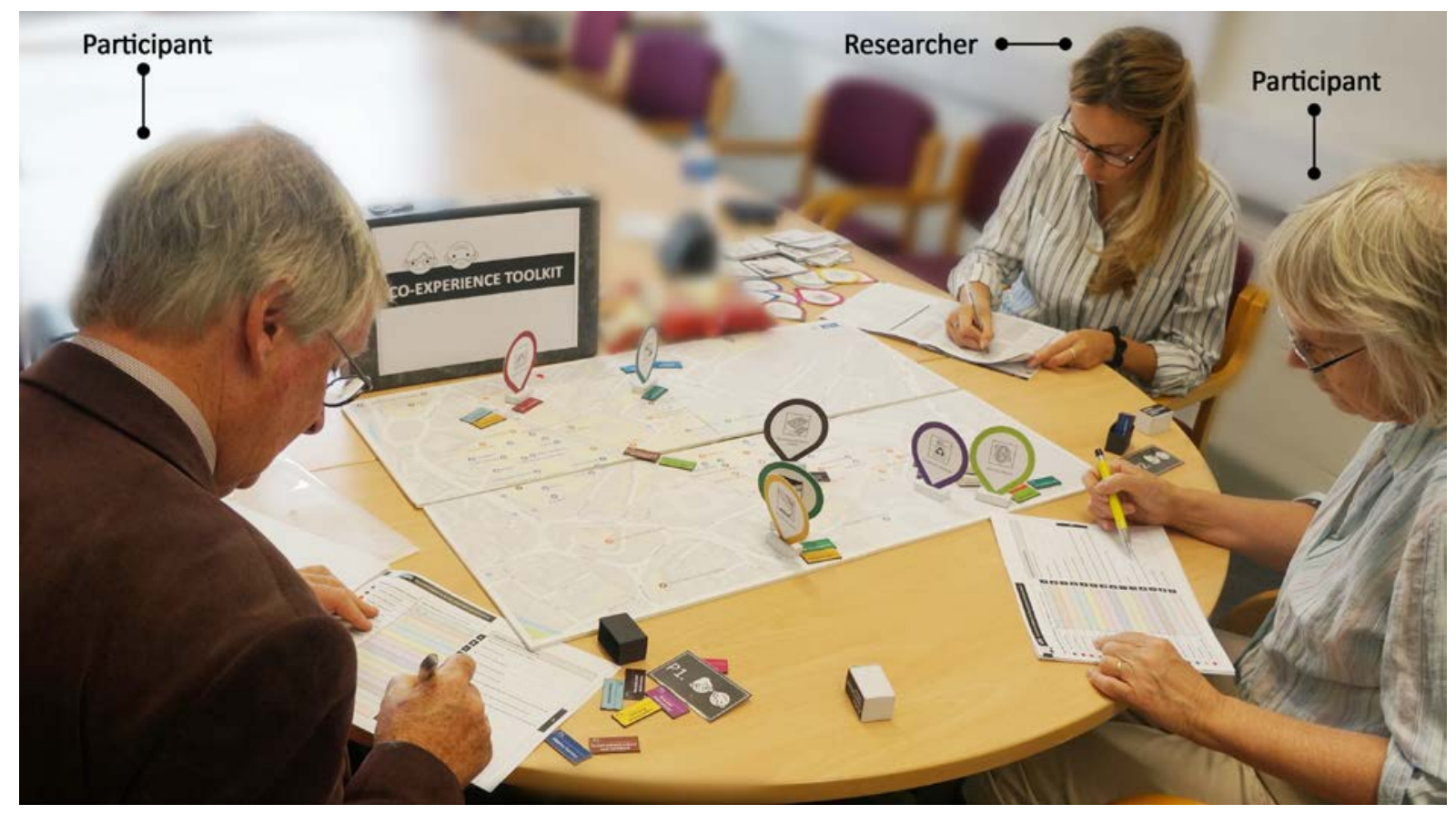

Figure 3 Test of the co-experience toolkit

\subsection{Result and discussion}

Each of the workshops took around 45 minutes, and we observed the significant phenomenon in the workshops. Additionally, we analysed the user feedback in questionnaires and discussed advantages and disadvantages of the toolkit and its components in aspects of usage, design and information delivery. In terms of the creation, most users agreed that the toolkit was user-friendly, highly straightforward, simple and well explained with a good layout and physical components, and the colours were well coded. However, a few users commented that the guidance and terms presented by the tool were slightly confusing and the matrix tables of the 'Survey book' were slightly complicated to use in the beginning. Moreover, the 'Pins' assisted the researchers to find out the priority of the pavement factors by exploring how many participants identified a particular pavement hazard in a specific location. However, they did not enable the participants to identify a pavement issue in various locations; thereby it limited the operation of the participants. On the other hand, the tool allowed the users to identify the problems of the pavement environment, the impact of the pavement and the behaviour changes of the older adults as it provided detailed and well-explained information. The tool also allowed users to arrive at the recommendations to the pavements by giving a comprehensive list. Even though one research student found that the relationship between the behaviours and pavement factors was slightly ambiguous, many users indicated that the tool could clearly demonstrate the relationship. In terms of the data recording, many researchers found it was efficient, easy and quick to compile the data on the recording card. However, one researcher also preferred a digital format rather than a physical layout as he believed it would be easier to compare the result.

As for the output of the tool, the researchers felted that it served its purpose and it had helped them to expand their knowledge regarding the relationship between older pedestrians and pavement. It gave them a better understanding towards the needs of elderly people and to suggest improvements to the pavement. Furthermore, the researchers would develop their work with the relevant response of the participants. For example, they would make a checklist or a guideline for designing inclusive environments for older adults, and relate the results to the body strength, health and other personal conditions of different participants.

In addition to their comments, we observed that even though the toolkit aimed to serve as a coexperience study, some participants did not cooperate with each other well in generating ideas and 
discussing ideas as expected. According to our analysis, this happened because of the design of the 'Survey book'. It efficiently facilitated the participants to have answers to the study questions.

However, some participants were less likely to think about, or expand their responses, or talked to others in the group when they selected their preferences from the provided tables.

\section{Development of the co-experience toolkit}

According to the analysis result and user suggestions, we redesigned the toolkit by developing its design, form, usage and communication. In addition to the previous version, the new toolkit offers 6 participant code badges to be used to represent the participants with a number, such as "P1" (participant one). Moreover, it provides 7 user instructions ( 6 for the participants and 1 for the researcher) that introduce the components and a use flow of the tool. Furthermore, a new 'Cardpack' was created by integrating the function of the 'card-pack' and 'pins' in the previous toolkit. Each card set in the new 'Card-pack' was made up of a 'Folding card' and six 'Mini cards'. The folding cards are used to explain the pavement factor and to identify the hazards that influence elderly pedestrians' walking in a pavement environment. The mini cards are applied to further confirm the issues in particular locations of the pavement environment. Lastly, the improved version provides 17 group survey cards for replacing the individual survey books. The survey cards are categorised into: sixteen 'Survey Card (1)' are used to investigate the adverse effect of the pavement factor and explore behavioural changes of participants, and one 'Survey Card (2)' is used to collect the suggestions to improve the pavement environment. Besides the revised materials, the researcher would also be given a recording card that is kept in the same design as its former vision. What else remains is that the researchers must pre-prepare a local map of a pavement environment along with the new toolkit.

\subsection{Improvements to the co-experience toolkit}

Figure 4 displays the new version of the toolkit and shows the differences between the developed toolkit and the former one. First of all, we abolished the 'Landmarks' as the researchers declare that the 'Landmarks' had the same function as the 'Pins' while excluded some pavement factors that identified by the 'Pins'. However, all identified pavement issues should be further studied. Secondly, more pictures are used in the instruction enabling users to easily and quickly recognise the information and keep it in a longer-term memory (Dewan, 2015). Additionally, we modified the personal 'Survey books' to group 'Survey cards' in order to encourage discussions and idea generation among the participants. The function of the group 'Survey card' remains the same, although it has now been redesigned with a circle layout to ensure that all users could read it from different angles and to be fully involved in the group discussion and exercise. It encourages researchers to be more active to explore extra findings in the survey. To guarantee the data is collected properly in the group interaction, we additionally created 'Code badges' for the participants to distinguish their role when giving their responses. Moreover, the toolkit has also been revised to allow users to position the pavement issues in various certain sites with the commonly-used 'Mini cards' rather than using the personally-used 'Pins'. Comparing to the former version, the researchers can record the amount of the locations where presenting the pavement factor and the number of the participants who identified the factor on the 'Survey cards' rather than in the 'Recording book'. Therefore, the correlation between each pavement factor and the participants (elderly pedestrians) would be more clear and specific. 


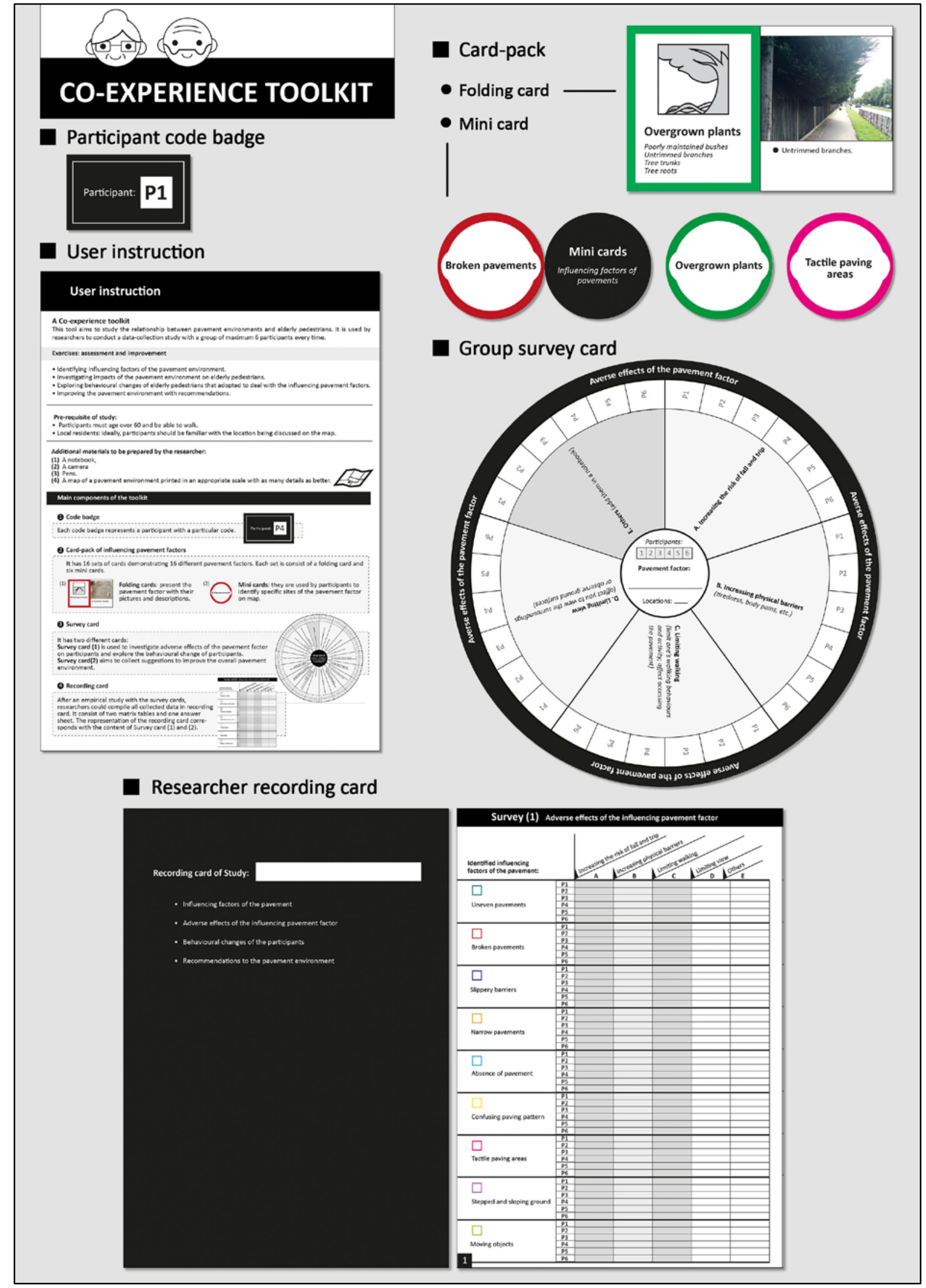

Figure 4 Developed version of the co-experience toolkit

\section{Conclusion}


From this study, we extend the findings of pavements and walking behaviour and develop a coexperience tool that not only identifies problems also provides practical recommendations to improve the pavement. The toolkit offers a new opportunity for researchers to listen to the needs of the elderly pedestrian. It is a heuristic tool allows users to participate in a co-experience study based on a localised area using a printed map for reference. Initial test shows that the toolkit has received a lot of positive feedback; even so, it has been further optimized. Although the studies used a small sample of participants, we have provided a representative result from each user group. In future works, we will involve broader user groups in the usability testing of the latest developed toolkit.

\section{References}

Arthur, J. (2012). Research Methods and Methodologies in Education. London: Sage publications.

Bayliss, D. (2015). The Condition of England's Local Roads and how they are Funded, (November), 52.

Corbin, J., \& Strauss, A. (2015). Basics of qualitative research (pp. 160-164). Los Angeles: SAGE.

Choi, E. (2012). Walkability as an urban design problem. Understanding the activity of walking in the urban environment.

DMRB. (2016). Design Manual for Roads and Bridges Volume 7 Pavement Design and Maintenance Section 2 Pavement Design and Construction Instructions for Use Footway and Cycleway Design, 7(February 2016).

Dewan, P. (2015). Words Versus Pictures : Leveraging the Research on Visual Communication. Partnership The Canadian Journal of Library and Information Practice and Research, 10(1), 1-10.

DfT. (2007). Manual for Streets. London: Thomas Telford Publishing.

Ewing, R., \& Cervero, R. (2010). Travel and the built environment. Journal of the American Planning Association, 76(3), 265-294. https://doi.org/10.1080/01944361003766766

FixMyStreet. FixMyStreet. Retrieved from https://www.fixmystreet.com/

Fan, S., \& Lu, Y. (2017). You Are Not Alone : the Impacts of Danmu Technological Features And Co-experience On Consumer Video Watching Behavior You Are Not Alone : the Impacts of Danmu Technological Features And Co-experience On Consumer Video Watching Behavior.

Frank, L. D., Sallis, J. F., Saelens, B. E., Leary, L., Cain, K., Conway, T. L., \& Hess, P. M. (2010). The development of a walkability index: application to the Neighborhood Quality of Life Study. British Journal of Sports Medicine, 44(13), 924-933. https://doi.org/10.1136/bjsm.2009.058701

Grinyer, L. (2016). Designing a toolkit for policy makers - Policy Lab. Openpolicy.blog.gov.uk. Retrieved from https://openpolicy.blog.gov.uk/2016/01/29/designing-a-toolkit-for-policy-makers/

Gray, D. (2014). Doing research in the real world (3rd ed., p. 422). London: SAGA.

Hussein, A. (2009). The use of Triangulation in Social Sciences Research: Can qualitative and quantitative methods be combined? Journal of Comparative Social Work, 1, 1-12.

IBM Design Research | Resources | Toolkit. (2017). IBM Design Thinking. Retrieved from https://www.ibm.com/design/research/resources/toolkit

I'DGO. (n.d.). Design Guide 002 Bus Stops.

I'DGO. (2010). Inclusive Design for Getting Outdoors. Do gardens matter?

London Borough of Hillingdon - Report potholes or damage. Hillingdon.gov.uk. Retrieved from http://www.hillingdon.gov.uk/article/25657/Report-potholes-or-damage

London Borough of Hillingdon- Street Champions. Hillingdon.gov.uk. Retrieved from https://www.hillingdon.gov.uk/streetchampions

Luoma, J., \& Peltola, H. (2013). Does facing traffic improve pedestrian safety? Accident Analysis and Prevention, 50, 1207-1210. https://doi.org/10.1016/j.aap.2012.09.023

Lo, R. H. (2009). Walkability: what is it? Journal of Urbanism: International Research on Placemaking and Urban Sustainability, 2(2), 145-166. https://doi.org/10.1080/17549170903092867

Mitra, R., Siva, H., \& Kehler, M. (2015). Walk-friendly suburbs for older adults? Exploring the enablers and barriers to walking in a large suburban municipality in Canada. Journal of Aging Studies, 35, 10-19. https://doi.org/10.1016/j.jaging.2015.07.002

Miles, M., Huberman, A., \& Saldana, J. (2014). Qualitative Data Analysis. Thousand Oaks, Calif.: Sage.

Oxley, J., \& Hern, S. O. (2016). Fall-Related Injuries While Walking in Victoria, (March). https://doi.org/10.13140/RG.2.1.2530.9044

Pollock, A. (2012). The value of well-designed outdoor spaces. Access by Design, 133, p.11.

Ravitch, S., \& Carl, N. (2016). Qualitative research: Bridging the Conceptual, Theoretical, and Methodological. Los Angeles [etc.]: SAGE. 
Rackliff, L. (2013). Deriving and validating performance indicators for safety mobility for older road users in urban areas, 10024745. Retrieved from

http://ezproxy.nottingham.ac.uk/login?url=https://search.proquest.com/docview/1774246183?accountid= 8018 http://sfx.nottingham.ac.uk/sfx_local/?url_ver=Z39.88-

2004\&rft_val_fmt=info:ofi/fmt:kev:mtx:dissertation\&genre=dissertations+\%26+theses\&sid=ProQ:ProQue

Shrestha, B. P., Millonig, A., Hounsell, N. B., \& McDonald, M. (2016). Review of Public Transport Needs of Older People in European Context. Journal of Population Ageing. https://doi.org/10.1007/s12062-016-9168-9

Silverman, D. (2010). Qualitative research. 3rd ed. London: Sage Publications, pp.132,133.

Spirduso, W., Francis, K., \& MacRae, P. (2005). Physical dimensions of aging. [S.I.]: Human Kinetics.

TFL. (2010). Pedestrian comfort guidance for London.

Curl, A. (2016). Europe PMC Funders Group Developing an audit checklist to assess outdoor falls risk, 169(3), 138-153. https://doi.org/10.1680/udap.14.00056.Developing

Wang, Y., Chau, C. K., Ng, W. Y., \& Leung, T. M. (2016). A review on the effects of physical built environment attributes on enhancing walking and cycling activity levels within residential neighborhoods. Cities, 50, 115. https://doi.org/10.1016/j.cities.2015.08.004

About the Authors:

Lulu Yin is pursuing her doctoral studies at Brunel University London. Her research focuses on designing a co-study toolkit to investigate the walking environment of pavements and the walking behaviour of elderly pedestrians.

Eujin Pei is the Programme Director for the BSc Product Design and BSc Product Design Engineering courses at Brunel University London. He is a Chartered Engineer and a Chartered Technological Product Designer possessing considerable expertise in leading industrial collaborative projects. 